\title{
Tú eres de la puna y yo de la ciudad Educación secundaria urbana e interculturalidad en el Perú
}

\author{
Yoshi Sotomayor Torres (2018)
}

Lima: Fondo Editorial de la Universidad Nacional Mayor de San Marcos, 188 pp.

Tú eres de la puna y yo de la ciudad. Educación secundaria urbana e interculturalidad en el Perú es un libro de la poeta e investigadora peruana Yoshi Sotomayor Torres, publicado por el Fondo Editorial de la Universidad Nacional Mayor de San Marcos en octubre del año 2018.

El presente libro, producto de un estudio de investigación para optar por el grado de Licenciatura, tiene como principal objetivo proporcionar evidencia respecto de la necesidad de diversificar el diseño y desarrollo de programas educativos de carácter intercultural y bilingüe para adecuarlos a contextos educativos urbanos en el nivel secundario con el fin de mejorar los resultados de aprendizaje de los estudiantes con trayectorias educativas rurales en dicho contexto.

El enfoque del estudio fue cualitativo y su carácter descriptivo exploratorio. Así, a partir de la aplicación de técnicas de recojo de información tales como la observación participante, las entrevistas semiestructuradas, los grupos de discusión y los testimonios de vida, se logra recopilar información importante respecto del clima educativo de una institución educativa andina urbana caracterizada por la heterogeneidad de su población estudiantil.

Para ello, la autora analiza la convivencia diaria entre estudiantes provenientes de contextos socioculturales rurales (que son quechua hablantes) y urbanos (cuya lengua materna es el castellano) en un escenario educativo de la ciudad, como la Institución Educativa Manuel González Prada, ubicada en Huari-Áncash. A partir del análisis de las relaciones interpersonales, en la convivencia escolar se develan prácticas discriminatorias, prejuicio y rechazo hacia los estudiantes rurales por parte de los estudiantes urbanos, principalmente, por cuestiones lingüísticas. Los testimonios revelan que el papel de la lengua en un contexto educativo caracterizado por la presencia de dos idiomas históricamente enfrentados: el quechua (como idioma estigmatizado) y el castellano (como idioma impuesto) continúa siendo crucial para el logro de aprendizajes en los estudiantes.

No obstante, las muestras de relego y discriminación hacia estudiantes de procedencia rural dentro de la institución, según los testimonios de los estudiantes, se manifiestan, en gran medida, en la actitud de los propios docentes, quienes promueven un trato diferenciado entre ambos grupos de estudiantes. Así, se configura un clima educativo que desmotiva y no propicia el aprendizaje, lo que incide negativamente en los logros de aprendizajes de los estudiantes de trayectorias educativas rurales. Los altos índices de repitencia y deserción escolar se relacionan directamente con este factor trascendental. 
La autora enmarca su análisis en las relaciones de poder existentes en la sociedad, que reproducen cotidianamente, a nivel interpersonal e institucional, formas de relacionamiento basadas en la discriminación y la exclusión. La escuela continúa reproduciendo estos mismos paradigmas que rigen una sociedad homogeneizante, toda vez que su organización jerárquica y vertical continúa promoviendo la negación de la diversidad sociocultural, étnica y lingüística, y la superioridad de lo urbano frente a lo rural. Esta visión monocultural de la escuela, que niega y anula conocimientos provenientes de otras culturas distintas a la hegemónica, conduce a que los estudiantes rurales, en su afán por hacerle frente a un entorno educativo ajeno y hostil, desarrollen actitudes de automarginación y aislamiento, según la autora.

Los resultados develan que los prejuicios discriminatorios perjudican el desempeño no solo académico de los estudiantes rurales dentro de la secundaria urbana, sino que también limitan su desenvolvimiento social. A través de un análisis minucioso de la trayectoria escolar de los alumnos provenientes de la primaria rural, el estudio pone en evidencia que el sometimiento cultural y lingüístico continúa primando en la práctica pedagógica. Por ello, la investigación desarrollada hace hincapié en la necesidad de, más allá de diversificar las propuestas educativas de carácter intercultural, interculturalizar los currículos escolares, pues la secundaria urbana que, hoy por hoy, constituye un espacio social marcadamente heterogéneo, así lo requiere.

El libro está dividido en cuatro apartados. En el primero, se desarrolla las relaciones de tensión entre la complejidad sociocultural y el clima social en la escuela andina. En el segundo, se examinan las diferencias que se mantienen vigentes entre la educación rural y la educación urbana para luego analizar, a nivel específico, la situación de la EIB en el país. En el tercer apartado, se da cuenta de los aspectos metodológicos de la investigación y se describen las características propias del contexto educativo donde se desarrolló el estudio. Finalmente, en el último apartado, se presenta el análisis de los testimonios de los estudiantes de procedencia rural y urbana respecto de su convivencia dentro de la secundaria urbana.

La investigación desarrollada permitió el hallazgo de datos reveladores que merecen especial tratamiento para desterrar prácticas que, lejos de promover el respeto y la valoración de la diversidad, continúan perpetuando formas de hostigamiento frente a poblaciones históricamente postergadas e invisibilizadas.

La riqueza del libro radica en que, por un lado, aborda una temática de vigencia y relevancia actual para nuestro país: la necesidad de promover la interculturalidad no solo a nivel del ámbito educativo, sino de todas las instancias sociales, toda vez que la sociedad peruana sigue definiéndose por su imaginario marcadamente colonial: racista, clasista, discriminador. Por otro lado, el libro pone en evidencia los retos para la EIB en contextos urbanos. Pese a los importantes avances logrados en los últimos años con respecto a la Educación Intercultural Blingue, aún quedan tareas pendientes y una de 
las principales es, precisamente, trabajar la propuesta de educación intercultural para contextos urbanos, con especial énfasis en la secundaria urbana.

Los resultados del estudio son una invitación a repensar, formular y desarrollar nuevas metodologías de enseñanza y aprendizaje sobre la base de un enfoque intercultural crítico, que responda al contexto sociocultural local de los estudiantes de modo tal que se garantice un reconocimiento real de la diversidad cultural y lingüística que caracteriza al Perú.

\author{
Gustavo Trelles Velásquez \\ Universidad Nacional Mayor de San Marcos \\ gustavo.trelles@unmsm.edu.pe
}

